\title{
LA CUESTIÓN DEL NACIONALISMO ACTUAL, EL RACISMO Y LOS PROCESOS DE MOVILIZACIÓN POLITICA DE LAS IDENTIDADES ÉTNICAS EN BELICE: REFLEXIONES DE CAMPO
}

\author{
The Current Nationalism Issue, Racism and the Politics Mobilizations Processes of \\ Ethnical Identity in Belize: Reflections on the Field
}

\section{CARLOS CORREA*}

Fecha de recepción: 09 de agosto de 2017 - Fecha de aprobación: 23 de noviembre de 2017

\section{Resumen}

El propósito de este trabajo es analizar cómo se articulan los procesos de nacionalismo actual en Belice con manifestaciones de racismo. Se hace hincapié en la producción de identidades excluidas de los marcos de construcción nacional en el contexto de la movilización política de la etnicidad y de proyectos oficiales de corte nacionalista. Los criollos afro-beliceños han sido tomados como el centro de proyectos nacionalistas promovidos por el Estado en su período posterior a la independencia en el contexto de un discurso sobre multiculturalismo. Mientras otros grupos étnicos disputan espacios de representación dentro de estas construcciones de identidad nacional mediante la movilización cultural articulada con la promoción oficial de la diversidad. En ese sentido, el estatus de los criollos nos permite cuestionar las imágenes de la negritud y los descendientes de africanos comúnmente considerados marginados de los espacios de poder para mostrarnos cómo la dinámica histórica del colonialismo juega con categorías como la raza y la clase para dar forma a escenarios de negociaciones políticas en los cuales las poblaciones de origen africano, en algunas ocasiones, pueden ocupar espacios de predominio.

Palabras clave: nacionalismo, movilización, racismo, identidad, afro beliceños

\section{Abstract}

The purpose of this papers is to analyze how current nationalism's processes are articulated with racism displays in Belize. It stresses on the production of excluded identities from nation-building framework in the context of political mobilization of ethnicity and Official projects for the construction of national identity. Afro-Belizean Creoles have been taken as the center of nationalist projects promoted by the state in its post-independence period in the context of a discourse on multiculturalism. While other ethnic groups dispute spaces of representation within these national identity constructions through the cultural mobilization articulated with the official promotion of diversity. In that sense, the status of the Creoles allows us to question the images of blackness and African descendant people commonly thought of as marginalized from the spaces of power to show us how the historical dynamics of colonialism play with categories such as race and class for shaping scenarios of political negotiations in which populations of African origin, on some occasions, may occupy areas of predominance.

Keywords: nationalism, mobilization, racism, identity, creole afro-belizean

\footnotetext{
* Mtro. en Antropología Social. Doctorante en el Centro de Investigaciones y Estudios Superiores en Antropología Social, Distrito Federal, México. El artículo está enmarcado en el proyecto de investigación doctoral "Procesos de movilización política de las identidades étnicas entre los creoles de Belice". Correo-e: pedropetrucci@gmail.com
} 


\section{Introducción}

Apenas el 15 de mayo del año en curso, reporteros del noticiero 7 News Belize recibieron una carta de nueve miembros del Sindicato Público de Trabajadores (P.S.U por sus siglas en inglés), a través de la cual acusaban al presidente de la organización, Mr. Eldred Neal; un hombre creole afro-beliceño, de Racial Perjudice. La acusación se llevó a cabo después de que se conociera la grabación de una conversación sostenida entre el presidente de la organización sindical y otros dos miembros de la misma, en la cual afirmaban que los garífunas -un grupo étnico afro-indígena Beliceño- lideraban una campaña para monopolizar el poder en el país ${ }^{1}$. En la conversación se referían a las personas garífunas con comentarios despectivos y claramente racistas a partir de los cuales estos eran representados como un grupo codicioso y pendenciero. En consecuencia, los nueve suscritos de la carta -que dicho sea de paso pertenecían a la etnia garífuna- exigían la renuncia del líder sindical debido a sus "irresponsables declaraciones racistas que dejaban en desconcierto a la comunidad garífuna del país quien le había apoyado con votos durante su candidatura" (7NewsBelize, 15 de mayo, 2017).

Las alusiones al tema del racismo son recurrentes en la vida pública del Belice contemporáneo y tienen una historia, aunque breve, de intensas movilizaciones ${ }^{2}$. Tanto en los noticieros nacionales como en varias notas de prensa la denuncia del racismo o el "prejuicio racial" ha sido objeto de polémicas y controversia. Incluso varios trabajos académicos tanto de investigadores beliceños como extranjeros han advertido la existencia del racismo como elemento constitutivo de la sociedad beliceña y como una herencia directa del colonialismo, y su política del Divide and rule, que aún moldea las dinámicas actuales de su sociedad. Algunos de esos trabajos han señalado enfáticamente el origen colonial del racismo en Belice a través de la convergencia entre la etnicidad y la clase para el establecimiento de formas de distinción social visiblemente excluyentes (Shoman, 1987, 2000, 2009). Otros, han analizado los conflictos interétnicos de naturaleza racista entre varios grupos de la población mostrando el predominio de ciertos grupos étnicos sobre otros (Medina, 1997); la situación de desventaja y marginación social en la que se encuentra la población maya debido a un racismo estructural y sistemático que les afecta particularmente (Grünberg, 2002); el acceso desigual a la tierra por causa de herencias coloniales clasistas y racistas que conformaron etnicidades y formas excluyentes de administración del territorio (Barnett, 2001); las discriminaciones de "raza"/género mediante las cuales se borró la participación política de las mujeres en la construcción de la nación y la sociedad criolla (Macpherson, 2003) y las convergencias entre el racismo y el clasismo para la perpetuación de privilegios de poder que derivaron en un menosprecio hacia las identidades "negras" de origen africano dentro de la sociedad beliceña (Devon, 2012; Hyde, 1970).

Sin embargo, pese a la manifiesta presencia del racismo en la sociedad de Belice hay una carencia generalizada de trabajos sobre el tema. Las alusiones a este permanecen envueltas en un aura más anecdotaria que analítica, provocando que la vivencia del racismo sea una tensa realidad cotidiana experimentada de distinta forma por los beliceños y no un fenómeno social objeto de un escrutinio riguroso y una crítica más severa. Pese a la relativa buena integración y relaciones pacíficas entre los distintos grupos 
étnicos que conforman la sociedad beliceña, existen unas barreras cotidianas de identificación focalizadas en y por la etnicidad, como organización social de la diferencia cultural (Barth, 1976), imbricadas con relaciones económicas clasistas, que resultan en tratamientos tensos e intercambios sociales no exceptos de racismos entre sus grupos. Mientras que continúa vigente el histórico predominio de una elite "blanca" y "creole" que monopoliza los recursos económicos, políticos y los capitales de tierra contra una mayoría popular desposeída que se encuentra en niveles de marginación altos y condiciones desiguales de vida ${ }^{3}$.

Paralelamente a todo lo anterior, en la actualidad el Estado beliceño elabora proyectos para robustecer su institucionalidad, despojarse de las herencias coloniales y fortalecer su soberanía post-independentista. La construcción de una identidad nacional post-independentista, la cual parece una tarea "superada" por los países vecinos de la región, en Belice es apenas un proyecto en ciernes que se abre paso en un clima de inestabilidades socio-políticas y una dependencia económica del capital extranjero.

Sin embargo, un clímax de creciente optimismo y expectativas por estrenar la vida independiente llevó a las elites dirigentes, en su mayoría creoles, a emprender proyectos de fortalecimiento y elaboración de la identidad nacional. Para ello, re-elaboraron narrativas sobre el origen de la sociedad beliceña, se establecieron símbolos nacionales y se trabajó para generar un sentimiento nacionalista en cuyo fondo; no obstante, según señalan sectores emergente de grupos involucrados en iniciativas de afirmación de las identidades étnicas, existen exclusiones racistas que no garantizan una inclusión más amplia de otros grupos étnicos en los relatos y proyectos de corte nacionalista. Tradicionalmente, la población "creole" ha sido tomada como un símbolo de "identidad colonial y luego nacional" en Belice (Ashdown, 1990; Bolland, 1988; Cunín, 2010; Judd, 1992; Shoman, 2009). Su historia está relacionada con la consolidación misma del asentamiento británico, debido a la larga actividad de casi más de dos siglos de explotación forestal que permitió su fundación y en la cual los "creoles" participaron de manera activa; convirtiéndose en pieza clave dentro de la cadena de explotación de relaciones económicas y políticas que incorporaron a Belice, anteriormente conocida como la Honduras Británica, en el escenario geopolítico global de las colonias europeas y del acelerado capitalismo mundial (Bulmer-Thoman, 2012; Shomman, 2009; Toussaint, 1993, 2009).

Por su parte, aunque las cuestiones relativas a la identidad nacional, el racismo y la afirmación de etnicidades han sido revisadas por varios trabajos en y sobre Belice, a veces de manera aislada y otras intentando vincularlas (Phillips, 1996), en la actualidad no existen investigaciones que analicen las manifestaciones de racismos en el marco de procesos contemporáneos de construcción de estado-nación a través de la elaboración y reforzamiento de narrativas de identidad nacional. La identidad nacional y su elaboración se ha vuelto una preocupación de las elites políticas dirigentes y de esas colectividades étnicas organizadas de la sociedad civil en Belice. Sin embargo, después de una serie de trabajos realizados en los 90' por investigadores "extranjeros" en su mayoría, poco interés ha suscitado la examinación de esos procesos en la actualidad. La importancia de examinar el lugar que ocupen ciertas etnicidades dentro de las narrativas de elaboración nacionalista radica en que las identidades étnicas que encarnan los 
referentes nacionalistas representan espacios de poder que permiten legitimar proyectos de construcción y reproducción del Estado (Abrams, 1988; Scott, 1998; Steinmetz, 1999) en los cuales la administración de la diversidad implica manifestaciones de racismos cuando esa diversidad es anulada o no encuentra espacios de representación plenos.

El objetivo de este artículo es analizar la manera cómo se articulan los procesos de construcción de nacionalismo actuales en Belice con formas de racismos estatista en el marco de las iniciativas de movilización de las identidades étnicas en Belice y del fortalecimiento de un nuevo estado-nación post-colonial. Por lo tanto, en este texto quisiera responder dos preguntas: primero, ¿cómo se articulan los actuales procesos de construcción del nacionalismo en Belice y el racismo? Y, segundo, ¿Qué repercusiones tiene esa articulación para analizar el marco general de las movilizaciones étnicas en el país? Para responder a ello, primero haré una breve descripción sobre el origen y la formación de la sociedad beliceña para entender la complejidad de su sociedad colonial y ver cómo se relaciona ello con la especificidad de los proyectos nacionalistas actuales. Seguidamente, ubicaré las fases y períodos claves de las iniciativas de construcción del nacionalismo en Belice para centrarme concretamente en la fase actual. Tercero, abordaré analíticamente la relación entre actuales procesos de construcción de nacionalismo y racismo a través de la revisión etnográfica de varios proyectos oficiales para construir identidad nacional. Por último, esbozaré algunas líneas analíticas sobre la relación entre las iniciativas contemporáneas de nacionalismo, racismo e identidades étnicas para perfilar una reflexión sobre cómo se proyecta al sujeto étnico en las actuales políticas sobre la diversidad en el país. Las discusiones, datos y aseveraciones que presentaré son resultado de un trabajo de campo etnográfico realizado durante el período 2014-2016 en Belice. La etnografía a la que hago mención hace parte de mi proyecto de investigación doctoral sobre procesos de movilización de las identidades étnicas entre los creoles afro-beliceños cuyo objetivo fue analizar las estrategias de legitimación y las iniciativas de afirmación de las identidades étnicas de un sector de la población creole afro-beliceña, organizada bajo la figura del National Creole Council of Belize, para dilucidar su articulación con los procesos emergentes de movilizaciones étnicas en Belice y los proyectos oficiales de promoción de la diversidad étnica auspiciada por el Estado que pretenden elaborar una identidad nacional y una apuesta por el desarrollo. Así mismo se realizó una etnografía institucional de las cotidianidades del Instituto Nacional de Cultura e Historia ( $\mathrm{NICH}$ en adelante) y en especial, de una de sus divisiones: el Instituto de Investigaciones Sociales y Culturales (ISCR en adelante), máximo organismo en el país en materia de elaboración, diseño y plan de desarrollo de la política cultural e identitaria. La mayor parte del tiempo trabajé en la ciudad de Belmopán y en la Ciudad de Belice, así como en varias comunidades rurales ubicadas en el distrito de Belice y el Cayo los cuales congregan a población creole-afrobeliceña y mestiza en su mayoría ${ }^{4}$.

Argumento que las iniciativas nacionalistas en Belice comenzaron como una movilización popular contra las crudas condiciones que establecía el régimen colonial cuyas consecuencias fueron la exclusión y el racismo, la 
marginación de ciertas etnicidades no-creoles, la monopolización de la tierra por parte de los británicos, la negación de derechos ciudadanos y la precarización de las condiciones laborales. Sin embargo, con los triunfos paulatinos de la movilización popular nacionalista, la tarea de unificación e integración de territorios y grupos étnicos excluidos se convirtió después en una preocupación de las nuevas élites del Estado hasta el punto de que el nacionalismo dejó de ser un nacionalismo de vocación popular para convertirse en un nacionalismo estatista (Billing \& Núñez, 1998; París, 1999). En ese tenor, este nacionalismo estatista contemporáneo en Belice tiene como objetivo legitimar un proyecto de Estado que pretende administrar la diversidad étnica desde una lógica celebratoria de la multiculturalidad, pero atendiendo poco a desigualdades estructurales en la que se encuentran la gran mayoría de sus grupos étnicos. En ese contexto, las identidades étnicas se racializan al ser pensadas como esenciales y fijas, provocando expresiones soterradas de racismos que se reproducen desde lo institucional y, en el marco de las cuales, algunas etnicidades afro-creoles son puestas en el centro de las construcciones de las narrativas nacionalistas mientras se excluye a otras. Como consecuencia, se producen alteridades étnicas marginadas de los imaginarios de fundación de la nación, cuyo resultado, siguiendo a Paris (1999) son "formas institucionales de discriminación y exclusión de otras identidades" ( $p$. $65)$. En esa medida las emergentes formas de movilizaciones étnicas en Belice constituyen un intento por debilitar "el modelo de sociedad creole que se había instaurado mediante la exclusión de otras etnicidades como las mayas y las garífunas" (Cunin, 2010, p. 174). Por otro lado, esas movilizaciones se articulan a los proyectos generales de promoción de la diversidad promovida desde el Estado en los cuales el sujeto étnico es representado desde la folclorización y la esencialización de sus identidades, siguiendo una lógica auto-gerencial y auto-gestiva que delega en ellos mismos la responsabilidad para lograr el "desarrollo de su cultura" y que transita hacia la mercantilización de la etnicidad (Comaroff \& Comaroff, 2009) y el formateo de las identidades (Hoffmann, 2008).

El lugar que ocupa la "afrodescendencia" en Belice, entendida como una construcción social anclada en los discursos sobre el origen africano, la esclavitud, las resistencias al colonialismo y la "negritud" como conjunto de expresiones identitarias "afro" (Gudmundson, 2012), es ambivalente y se escapa de los modelos comunes que abordan el tema de "lo negro" en las culturas nacionales. Los creoles afro-beliceños son un grupo que representa tanto la marginación colonialista como el predomino de clase; la hegemonía étnico-racial y las resistencias y readaptaciones ante el colonialismo. Un cierto predominio cultural y socio-político del que han gozado los ubica en el centro de muchas de las formaciones nacionales siendo, en cierta medida, el referente obligado para pensar la "beliceñidad". Sin embargo, dentro del clima de emergentes movilizaciones étnicas que socaban la otrora "hegemonía creole" se vuelve a poner sobre la mesa la cuestión de la producción social de las minorías "afro" en el contexto contemporáneo del multiculturalismo y sus apuestas por el reconocimiento. 
1. Sobre el origen de la sociedad beliceña y el contexto social que posibilita el nacionalismo.

Belice es un pequeño país caribeño ubicado en Centro América; anglófono pero inserto en una región hispanófona; con una población de origen africana creole considerable en un contexto regional donde la imagen del "mestizo" caracterizó los proyectos de formación de las sociedades nacionales de sus países vecinos. Hasta el año de 1981 fue una colonia británica que pertenecía al grupo de otras "posesiones" británicas como Jamaica, Trinidad y Tobago, Las Bermudas, la Guayana inglesa, entre otras. Belice limita al norte con México, al Sur-oeste con Guatemala y al este con el litoral del mar Caribe. Antes de la llegada de los europeos (españoles y británicos) al territorio, varias denominaciones de indígenas mayas habían establecido señoríos y asentamientos en la región, dominando una vasta zona que comprendía desde la península de Yucatán hasta más allá del Petén y el Tipú rumbo a Guatemala (Bolland, 1992). Según varios historiadores, los primeros registros de la actividad de británicos en el territorio de Belice datan de la primera mitad del siglo XVII, poco después de que la piratería y el pillaje ultramarinos fueran suprimidos por medio de la firma del Tratado de Madrid en 1670, contraído entre España y Gran Bretaña (Shoman, 2009).

Alrededor de la desembocadura del río Belice se instalaron los primeros colonos británicos conocidos como los Bayman con el fin de vincularse a la creciente industria de la economía forestal que nutría a las metrópolis europeas. La extracción y el comercio del Palo de Campeche - Logwood, una madera de la cual se extraía un pigmento colorido valioso para el comercio textil en Europa, marcó el inicio de la industria forestal colonial que daría paso a la forma- ción y consolidación del asentamiento británico (lyo, Froyla \& Humpherys, 2007; Murray, 2006). En sus primeras etapas, estos campamentos semi-estacionarios de leñadores británicos y sus esclavos negros eran considerados ilegales, sin embargo, pronto aquellos primeros colonos obtuvieron una concesión de la corona española para la extracción de madera bajo la condición de no establecer asentamientos permanentes en el territorio. Estas concesiones quedaron establecidas en el Tratado de Paris de 1779 y posteriormente fueron ampliadas y ratificadas nuevamente mediante la convención de Londres de $1787^{5}$.

El rápido agotamiento del palo de Campeche dio paso a la exportación de otra madera valiosa para la industria forestal: La Coaba. La mayoría de los historiadores de Belice coinciden en que fue a partir de la exportación y el comercio de la Caoba cuando Belice logró consolidarse como un asentamiento británico menos rudimentario, experimentando a su vez, un crecimiento poblacional y económico considerables que lo llevaría a convertirse formalmente en una colonia británica en 1882, al final del siglo XIX. Fue durante este siglo que se establecieron las primeras instancias de administración colonial y se disparó tanto el comercio como la importación de personas esclavizadas, quienes ahora eran traídos directamente de la región noroccidental de África, principalmente de Nigeria y el Congo ${ }^{6}$. El asentamiento adquirió un control político y económico británico y un dominio cultural creole a través del cual se definió la identidad cultural de la colonia, sobresaliendo el predominio de ese grupo étnico-racial durante el siglo XIX y todo el siglo XX.

Aquella floreciente economía forestal empezó a consolidar una forma de organización social en el asentamiento que fue conocida como 
forestocracia (lyo, Froyla \& Humphreys, 2007; Shoman, 2009). Los británicos involucrados en el comercio forestal rápidamente se convirtieron en la fuerza económica y política del asentamiento seguidos por sus descendientes inmediatos: los creoles, quienes surgieron de la unión entre británicos y africanos ${ }^{7}$. La monopolización de grandes porciones de tierra en Belice por parte de los británicos, el surgimiento de un régimen colonial basado en la explotación de mano de obra esclavizada y la creación de políticas de administración colonial que mantenían separada a la población con el fin de establecer formas de división racial del trabajo se convirtieron en las expresiones fundamentales de la opresión y el racismo coloniales. En ese contexto, los británicos eran los dueños del asentamiento, los creoles, administradores de los bienes coloniales, y Belice City o el Pueblo de Belice, el centro del poderío político, económico y cultural de la sociedad colonial. Mientras tanto el resto del territorio permanecía aislado, marginado y bajo unas precarias condiciones laborales que incrementaron los resentimientos interétnicos entre los principales grupos del asentamiento: mayas, garífunas, hindúes, chinos, y mestizos quienes arribaron al territorio durante el siglo XIX, momento en que la Honduras Británica alcanzó un crecimiento exponencial de su población.

Judd (1990) señala que la categoría creole fue introducida en Belice a partir del año 1809 con el fin de diferenciar a los descendientes de la mezcla entre británicos y africanos, que ya habían nacido en el asentamiento para finales del siglo XVIII, del resto de la población blanca y negra esclavizada. Define creole como "a person of negro ancestry [or] a person of mixed European and African ancentry" (Judd, 1990, p. 30). Los creoles son fundamentalmente aquellos "hijos ilegítimos" de hombres británicos que forzaban a mujeres esclavas africanas, empleadas en trabajos domésticos y de cultivo de hortalizas para el autoconsumo. Éstas permanecían largas temporadas solas en las casas de los hombres blancos y a su merced mientras sus maridos o parejas duraban largas temporadas internados en campamentos madereros y solo regresaban para la navidad. Muchos de ellos, aunque habían adquirido su libertad, se dedicaban de lleno a la industria forestal. Sus descendientes fueron identificados como "coulored people" o "free colored people".

En su mayoría, los creoles vivían en zonas "urbanas" y algunos se dedicaban también a la explotación de madera siendo dueños de contingentes de esclavos. Sin embargo, había creoles y "negros" empleados como esclavos y luego como aprendices en la industria de la extracción de madera. Estos eran descritos por las autoridades coloniales como "la columna vertebral de la colonia" y "su más efectiva fuerza laboral” (Bristone \& Wright, 1888, p. 199).

En efecto, aunque los creoles fueron desde el principio un grupo heterogéneo, tanto en aspectos relacionados con la apariencia física -el color de la piel y la procedencia, por ejemplo-, como por los roles sociales que ocupaban dentro de la sociedad colonial, se definían así mismos como "los fundadores de Belice y su cultura" o como "los primeros habitantes". Su innegable predominio no solo cultural sino económico, solo superado por los blancos británicos, les valió ser reconocidos por los otros grupos del creciente asentamientos como los "hijos de la corona" (Cunin, 2010; Shoman, 2009).

En la primera mitad del siglo XIX, los creoles se habían convertido en una élite hasta el punto que en 1831 alcanzaron los mismos 
derechos políticos que se reservaban para sí los blancos colonos. A partir de entonces, mediante mecanismos de distinción social relacionados con el estatus político y jurídico, aspectos económicos como el patrimonio familiar y comercial, y elementos culturales como el apego al sistema de valores anglosajón, entre los creoles de la élite y el resto de los demás grupos de la sociedad colonial se fueron gestando relaciones de exclusión que incrementaron la brecha social entre estos y los demás grupos incluyendo a los creoles de los sectores más bajos. Al respecto lyo, Froyla y Humphreys (2007) señalan que:

Los creoles fueron tan racistas como los blancos colonos. Aun cuando tuvieron madres "negras" esclavas y padres blancos, ellos rechazaban su conexión con su procedencia negra-esclavizada y quisieron unirse a las elites blancas. Extremadamente orgullosos de su riqueza, educación británica, su lealtad a Inglaterra, su "buen carácter" y en general, su ancestría británica (p. 296) ${ }^{8}$.

A través del control de la tierra, la emisión de leyes sobre la propiedad y el trabajo y mediante alianzas políticas, tanto creoles de elite como blancos colonos desplegaron un control político y un predominio cultural en el asentamiento (Shoman, 2009). En consecuencia, para varios grupos de negros libres y de otros creoles de las clases más empobrecidas, las condiciones de trabajo eran casi las mismas que aquellas que mantenían bajo la esclavitud que fue abolida a través de los decretos de emancipación desde Londres en 1838 (Shoman, 2009).

Para finales del siglo XIX en ocasión de la conmemoración de la emancipación y los 50 años de abolición de la esclavitud, entre 1888 y 1893, se celebró dentro de la sociedad colonial, The Emancipation Jubilee y el People's Hall Project. Ambas celebraciones, presididas $y$ organizadas por Simon Lamb, un hombre creole de la clase media junto con maestras y mujeres creoles, empezaron a poner el énfasis en los derechos que la "población coulored [creole] de la colonia" tenían. A partir de ese momento, alrededor de lo "creole" se empezarían a gestar las primeras formas de afirmación de una identidad grupal racializada imbuida en una cuestión de clase. Macpherson (2003) subraya que los discursos que rodearon la celebración del People's Hall Project hacían énfasis en "el orgullo por los ancestros negros, la participación de las mujeres y el realce de los Baymen" (p. 115). Aquellos primeros creoles de la clase media comenzaron a promover un discurso sobre la ascendencia y la procedencia. Se definían ellos mismo como los "hijos de los bayman", aquellos primeros colonos que establecieron el asentamiento con la intención de ser reconocidos como hijos de la corona y sus auténticos pobladores. En ese sentido, se construía las primeras narrativas identitarias de la nación colonial que hacían énfasis en: a) Un discurso sobre la supuesta unión entre la "raza" de los baymen y la "raza" de los esclavos para defender el asentamiento de las autoridades españolas, b) la promoción de una hegemonía del grupo creole, como los descendientes de aquellas "razas" honorables, suavizando la memoria de la esclavitud y sus atrocidades mediante la instauración de un mito de fraternidad entre los esclavos y sus amos "blancos" alrededor de la batalla de St. George's Caye y c) el incremento de las divisiones de clase entre los creoles de la élite, los de clase media y aquellos de los sectores populares, quienes enfrentaron el recrudecimiento de las políticas coloniales que estigmatizaban muchas de su expresiones culturales, la mayoría de ellas de origen africano. 
En la actualidad, según datos del último censo de población realizado en el 2010 , dentro de las fronteras del territorio beliceño habitan 356. 600 personas de las cuales el $54.8 \%$ viven en áreas rurales y el $45.2 \%$ en urbanas. Del total de ellas, mestizos, creoles, mayas y garífunas son los grupos étnicos más numerosos. A través del criterio de auto-adscripción, el $52.9 \%$ de su población se identifica como "mestizo"; es decir, 170.446 personas reconocen sus vínculos con la cultura de origen hispano siendo el grupo étnico mayoritario. Seguidamente, $26 \%$ se identifica como "creole", unas 83.460 personas que, por su parte, reconocen sus vínculos con las culturas afro caribeñas y anglófonas, conformando el segundo grupo étnico más grande en el país. Luego, el $11.3 \%$ se definen como mayas (ketchi, mopan y yucatecos); y, por último, el $6.1 \%$ como garífunas siendo estos últimos los grupos indígenas más importantes del país.

Además de lo anterior, el censo también señala la existencia de otros grupos étnicos viviendo en Belice. Asiáticos (japoneses) y chinos (taiwaneses), 1.0\%; caucásicos o "blancos", $1.2 \%$; east indian (hindúes), $3.1 \%$ y menonitas (de origen alemán), $3.5 \%$. También el censo menciona un porcentaje mínimo de población de origen sirio-libanés. La totalidad de sus grupos étnicos se encuentran distribuidos en los 6 distritos en los que está dividido política y administrativamente el país: Corozal, Orange Walk, Belize, Cayo, Stan Creek y Toledo (Belize Census Report, 2010).

Inmediatamente después de la independencia, durante el inicio de la década de los 90', la cuestión de la diversidad cultural del país fue objeto de interés de la dirigencia política y del sector internacional. Entre los años 1990 y 1992 se lanzaron varias iniciativas de consulta popular auspiciadas por el gobierno, cuyos miembros principales pertenecían al partido People United Party (PUP), con apoyo de la UNESCO. Estas iniciativas fueron conocidas como Realising (1991) y What the people say (1992), simultáneamente (Cunin \& Hoffmann, 2014). Su objetivo fue perfilar las primeras acciones para construir y consolidar una "identidad nacional". Seguidamente, se crearon las instituciones que se encargarían de dirigir ese proceso, tales como el Consulado Nacional de las Artes que, a partir del 2003, se convertiría en el Instituto Nacional de Cultura e Historia (NICH), etc. En ese clima optimista, de entre varios de los principales grupos étnicos del país surgieron iniciativas organizativas que adoptaron la figura de concejos locales a través de los cuales se promovían la lengua, las prácticas religiosas, las formas de organización alrededor del territorio y la tenencia de la tierra junto con expresiones de carácter cultural como danzas y prácticas culinarias.

Mayas, garífunas y creoles de los sectores populares en Belice empezaron a movilizar políticamente sus identidades étnicas mediante estrategias como la afiliación a redes internacionales indígenas y afrodescendientes. La población garífuna adquirió notorio reconocimiento a nivel internacional hasta el punto de que en 2001 su lengua y cultura fueron declaradas como patrimonio Inmaterial de la Humanidad por la UNESCO. Por su parte, los reclamos por el derecho al acceso a la tierra y el reconocimiento de formas autóctonas de regencia de sus territorios hechos por la comunidad maya al sur del país fueron reconocidos y amparados por un fallo del tribunal supremo de justicia en Belice en el 2007 y posteriormente, fueron ratificados y ordenados por la Suprema Corte Interamericana de Derechos de los Pueblos Indígenas y Tribales 
en octubre de 2015 y la Corte de Justicia del Caribe a partir del cual los mayas históricamente obtenían un triunfo contra el Estado de Belice que hasta ese momento no había garantizado el cumplimiento de sus derechos.

Para el caso de los garífunas, la promoción que hacen actualmente de una lengua, ritos religiosos, pertenencia a una comunidad transnacional (presente en Honduras, Guatemala, Nicaragua, Belice y EE.UU), su música (ritmos como la punta, parranda, punta rock), etc., se utiliza para señalar su diferencia y "autenticidad" como una cultural Beliceña transnacional producto de la diáspora africana. Su historia los ubica en una situación identitaria ambigua al ser clasificados y auto-clasificarse como indígenas y descendientes de africanos (Anderson, 2007; Izard, 2004, 2010). En sus esfuerzos por movilizar políticamente sus identidades, además del reconocimiento internacional de su cultura por la UNESCO, su movilización también ha obtenido un protagonismo nacional. En Belice se estableció el Settlement Day (una festividad garífuna promovida a fiesta nacional en 1977) que celebra su llegada a suelo beliceño en 1802. Esta festividad les ha valido un creciente protagonismo entre la población nacional y entre los miles de visitantes que cada año llegan para observar la conmemoración su llegada a Belice.

Por su parte, los mayas en Belice trabajan por la valorización de su historia y cultura, en el marco de un turismo patrimonial (explotación de sitios arqueológicos mayas). Participan de una red de ONG's mayas mesoamericanas y se definen, así mismos, como los "primeros pobladores de Belice". De igual manera, han mantenido un arduo conflicto con el Estado Beliceño por el reconocimiento a sus derechos sobre el territorio y la autonomía de sus formas de autogobierno, en el contexto del cual, los recientes fallos de las cortes suprema beliceña y la corte interamericana a su favor, han consagrado su legitimidad como un actor étno-político importante en el país.

En consecuencia, las emergentes movilizaciones de los principales grupos étnicos en Belice, sumado al crecimiento de la población mestiza, que en la actualidad representa el grupo más numeroso del país, han alertado a la población creoles de los distintos sectores sociales sobre una posible "latinización del país". También han supuesto su pérdida de hegemonía entre las formas de representación de la identidad nacional y su estatus político como grupo. De manera que, entrando un poco en la misma dinámica de afirmación de la diferencia y construcción de una "etnicidad", en algunos sectores de los grupos creoles se adoptaron también estrategias de movilización de la identidad étnica. Así, en 1995 se creó la asociación el National Kriol Council of Belize. El propósito de esa organización es promover la lengua y la cultura creoles para armonizar con los otros grupos étnicos nacionales. Esta organización resalta aspectos de la cultura creole; la vuelve a la ruralidad y la sitúa en pueblos, delineando una serie de rasgos culturales y buscando el origen africano de cada práctica identitaria en la música, cantos, bebidas y danzas. En ese tenor, un cierto número de localidades rurales y campesinas, ubicadas a las orillas del río Belice y el New River son presentadas como las "auténticas" comunidades creoles que han conservado más "prístinamente" los legados socio-raciales y culturales africanos que ahora se presentan en una lógica de la diferenciación que los distancia incluso de otros creoles que residen en zonas urbanas o en ciudades como Belice City. 
Las movilizaciones de las identidades étnicas en Belice se articulan de igual forma con las actuales políticas de construcción de nacionalismo en un clima de proyectos estatales de desarrollo que han apostado al turismo como su principal fuente de crecimiento. Después del colapso de la industria forestal que duró más de dos siglos, Belice solo se mantiene de la producción de cítricos, bananos y caña de azúcar. Incipientes proyectos de agricultura no son suficientes para el crecimiento del país que se vio estancado a partir de los 90'. De modo que, hoy día son más urgentes los proyectos de construcción de una identidad nacional a partir de un plan de desarrollo que involucra a varios de sus ministerios e instituciones públicas. Entre ellas el $\mathrm{NICH}$ ha lanzado una política cultural que tiene como objetivo "descentralizar el modelo de cultura" y promover una cultura para el desarrollo y a través de ella "proveer el marco general para la construcción de una identidad nacional" (Belize Cultural Policy, 2014, p. 6-11).

\section{Fases de los procesos de la construcción del nacionalismo en Belice.}

Según las teorías generales que abordan el nacionalismo este puede ser entendido como "ideología, un movimiento, un sentimiento y como un proceso de construcción nacional" (Smith, 2000, p. 329). Esos enfoques pueden agruparse en cuatro tipos: los enfoques modernistas o perennialistas, que hacen énfasis en explicar el origen de la nación; los constructivistas o reificadores, que discurren sobre la naturaleza de la nación, los estructuralistas, que tratan de explicar las causas por las cuales las naciones son fundadas; los enfoques funcionalistas, que se centran en explicar cuál es la función y los mecanismos de dominación y cohesión que mantienen las naciones; y por último, los enfoques posmodernos, que han abordado todos los aspectos anteriores pero desde un perspectiva constructivista-subjetivista e historicista (Márquez, 2011; Smith, 2000). En este trabajo se concibe el nacionalismo fundamentalmente como un conjunto de referentes simbólicos, psicológicos e ideológicos que dan paso a una serie de prácticas rutinarias que reproducen en la cotidianidad el sentimiento de pertenecer a una comunidad imaginada constituida en el marco de un estado-nación (Paris, 1999; Billing \& Nuñez, 1999; Anderson, 1993).

Las etapas de los procesos de construcción del nacionalismo en Belice se pueden resumir en tres: En la primera etapa se perfila una crítica contra el racismo de la sociedad Beliceña producto de la explotación laboral, la opresión racial que sufría la población negra y el acaparamiento del capital y la tierra en manos extranjeras. Esta etapa comprende de 1919-1930. Durante esta etapa empezaron las primeras movilizaciones sociales en el corazón de la sociedad colonial y el recrudecimiento del régimen imperial británico. La influencia de las ideologías pan-africanistas como las de Marcus Garvey significaron una crítica a la ideología racista que soportaba el proyecto colonial y que oprimía particularmente a la población "negra" debido a que los tomaba como la fuerza laboral más prominente de la colonia al tiempo que reproducía formas de exclusión sistemáticas. En conversaciones con líderes de las organizaciones creoles y con miembros del ISCR, quienes realizaban trabajos históricos sobre el país, la reflexión sobre el colonialismo y la manera como implicó formas de opresión profundas en Belice, fue una referencia recurrente donde se señalaba el racismo como una de las causas de la marginación en Belice. 
En Belice el colonialismo fue tan fuerte que nada quedaba en el país. Las autoridades coloniales tomaban todo lo que se producía, principalmente madera, y lo llevaban a las metrópolis europeas. Después la injerencia de los norteamericanos pasó a ser como un segundo régimen. Dependíamos de las importaciones mientras ellos acaparaban tierras y se llevaban las materias primas del país. Tanto creoles como el resto de los grupos en Belice sufrían los estragos del racismo que aquí significa sobre todo despojo y marginación (Mr. Pinelo. Entrevista. 14, de septiembre, 2016) $)^{9}$.

La segunda etapa de los procesos nacionalistas es propiamente la fase de la movilización popular en torno a la exigencia de derechos laborales, ampliación de la ciudadanía, crítica al predominio de las elites creoles y británicas; reclamos por integración y reconocimiento de los otros grupos étnicos relegados de las instancias de representación legislativas y políticas. Esta etapa va de 1931-1964. Durante esta etapa los sentimientos anti-colonialistas, por un lado, así como la aspiración nacionalista, por el otro, marcaron el inicio de la política moderna en Belice (Shoman, 2004, 2009). El surgimiento del primer partido político de Belice, el People's United Party (PUP), con el apoyo del movimiento sindical emprendió la dura tarea de encaminar a la nación a su independencia. En el transcurso de ese período, por divergencias entre la dirigencia del partido se conformó el United Democratic Party (UDP) quien se convertiría en la máxima fuerza opositora del primer partido $y$, a partir del cual, se instauraría una forma de gobierno principalmente bi-partidista con alternancia de poderes.

Aunque en Belice la orientación política de los partidos no es abiertamente étnica, según la historiografía de la política moderna en el país, el primer partido, el PUP, era principalmente de vocación centro-izquierdista y estaba asociado con la población mestiza o, por lo menos, pro-integracionista. Por su parte, el UDP, cuyo principal líder fue miembro del comité del primer partido político, es asociado con las élites y los intereses de los creoles en Belice. Normalmente se acusa al primer partido de promover una "latinización del país" debido a su actitud de favorecer y apoyar la solicitud de refugiados mestizos centro americanos durante los 80' y 90'. También es acusado de estrechar lazos con Guatemala y Centro América, en especial, de querer ceder territorio beliceño a los reclamos guatemaltecos sobre las tierras en Belice. Por su parte, el UDP es acusado de ser un partido pro orientación británico, tibio ante las opresiones coloniales, sobre todo cuando en sus inicios manifestó que la sociedad beliceña no estaba preparada aún para adquirir su independencia (Shoman, 2009). Este último es el partido que está en el poder actualmente en Belice.

La tercera y última etapa de los momentos de construcción del nacionalismo comprende varias acciones. Entre ellas se aprecia el esfuerzo por modernizar las instituciones nacionales, el fomento de una política de integración al capital global a través de planes de desarrollo del sector terciario y la emergencia de movilizaciones de las identidades de los grupos étnicos y sus apuestas por el reconocimiento. Esta etapa marca el final de los años 90' y abarca el período que corresponde hasta la actual fecha. En esta fase se crean los primeros proyectos abiertos por administrar la diversidad en el país depositario de una pluralidad étnica y una multiculturalidad de facto. Se crea el museo nacional de Belice y el Instituto Nacional de las Artes se convierte en el Instituto Nacional de Cultura e Historia (NICH) encargado de diseñar, ejecutar y desarrolla la política cultural en el país. En esta etapa se crean varias Casas de la Cultura 
en cada uno de los 6 distritos en los que se divide el país y se intenta agrupar y administrar a través de ellas las iniciativas populares de los grupos étnicos que se encuentran representados en cada una.

\section{Los procesos de construcción del naciona- lismo actuales y el racismo: una producción oficial de identidades excluidas y excluyentes.}

El nacionalismo en Belice es ahora un nacionalismo de Estado, aunque en sus orígenes empezó como una movilización popular de las clases obreras y como un reclamo de varios sectores de la población por ser integrados como parte de la nación. Anderson (1993) señala que "la nacionalidad" 0 , la "calidad de nación" al igual que el nacionalismo, son artefactos culturales que despiertan una legitimidad emocional profunda construida en base a significados y formas históricas cambiantes" (p. 21). Aunque la nación se presente como una formación "natural", esta es en realidad una construcción cultural que usa, alrededor del territorio, la tradición y la etnicidad, significados simbólicos duraderos para legitimarse como tal hasta volverse una vivencia cotidiana. En ese sentido, la "nación" es "una comunidad política imaginada, casi bajo la misma forma de lealtad y fervor con que se mira el parentesco y la religión, en la que sus miembros se sienten parte de un espacio político y territorial limitado y soberano" (Anderson, 1993, p. 23). Sin embargo, los nacionalismos son auspiciados por grupos de actores políticos, ya sean estos de procedencia popular o sean una élite del Estado. Por ello, la identidad nacional es construida e instrumentalizada con fines específicos para establecer y legitimar proyectos de estado-nación. Esta comprende una serie de elementos simbólicos que gozan de una materialidad en las rutinas cotidianas de los estados. Así, la identidad nacional es "un conjunto de discursos y prácticas, muchas de las cuales forman parte de la rutina de los estados-nación establecidos" (Billig \& Nuñez, 1998, p. 37).

En Belice contrastan el discurso abierto sobre la multiculturalidad y la integración de todos sus grupos étnicos con las acciones y proyectos oficiales para construir la identidad nacional mismos que, en opinión de varios intelectuales y personajes públicos de la sociedad civil, están demasiado "volcados a reforzar lo "creole" como garante de la "identidad nacional". Durante esta administración, regida por el Union Democratic Party (UDP) las iniciativas oficiales de promoción cultural, aunque parecen abiertas e incluyentes con todos los grupos étnicos del país, se orientan a reforzar nuevamente el predominio de lo "creole" como el sostén identitario de la nación. A pesar de que se ha logrado una integración pacífica de los grupos étnicos y no hay roces considerables entre ellos, el resabio de cierto predominio creole ha empezado a resurgir con las acciones de esta administración definida como "pro-creole". Así, Leonora, una mujer extranjera, propietaria de la única empresa editorial del país señala en una entrevista lo que sigue:

Tengo más de 40 años de vivir en Belice y he visto
los cambios que ha sufrido este país como una testigo
privilegiada. Por ejemplo, ya ahora la gente puede
hablar español con más confianza. Antes eso era mal
visto. Había un rechazo muy fuerte para todo aquel que
fuera spanisho latino. Los criollos decían que este país
era suyo. Pero a partir de los 90 'se empezó a generar
una identidad de unidad, a crear una imagen de un país
con múltiples culturas pero con una misma identidad, la
identidad de lo beliceño. Sin embargo, ahora he visto
que desde la actual administración en el NiCH se han
volcado fanáticamente a reforzar la identidad creole
y a apoyar todo proyecto que busque reforzar esa 
identidad. Se han hecho publicaciones y acciones que van dirigidas otra vez a mostrar a lo creole como el centro de Belice y su cultura y se han dejado de lado dentro de las narrativas nuevas nacionalistas el aporte de otros grupos como los mayas, los mismos mestizos y hasta los garífunas (Leonora, entrevista, Diario de Campo, marzo, 2015).

En consecuencia, ¿cómo se articulan los procesos actuales de construcción del nacionalismo con el racismo? Paris (1999) sostiene que "el racismo es el exceso constituyente o el suplemento interior del nacionalismo" (p. 65). El nacionalismo en Belice, que actualmente es un nacionalismo estatista, institucionaliza formas de discriminación en la medida que excluye/ incluye colectividades étnicas en posiciones centrales y otras en lugares periféricos de los relatos y símbolos que dan vida a las formaciones de la identidad nacional. En la construcción de los referentes nacionalistas juegan un papel central los actores sociopolíticos. La escuela pública, los medios de comunicación y el ejército, los institutos de Cultura e Historia de carácter público, las élites regionales y "los grupos locales de poder inciden en la selección de los símbolos nacionales, de héroes, y de una "historia oficial" en función de proyectos políticos que se tratan de legitimar" (Paris, 1999, p. 64).

La producción de identidades excluidas y excluyentes (Paris, 1999) y de regímenes nacionales de alteridad (López, 2011) instituyen jerarquizaciones y clasificaciones en el acceso a la "consciencia nacional" y a recursos sociales, así como a espacios de poder mediante los cuales hay etnicidades subordinadas y otras dominantes. El lugar que ocupan ciertos grupos en aquello que se denomina "la cultura nacional" o en las plataformas de representación política: como instancias de administración de la justicia, instituciones para la distribución de recursos sociales e instancias legislativas, se traduce en reconfiguraciones del poder para legitimar proyectos de estado-nación que repercuten en toda la "unidad política" Ilamada nación.

Las celebraciones nacionales de septiembre del año 2016 fueron un escenario para observar cómo las dinámicas del nacionalismo, con sus referentes y discursos, reforzaban el papel de los creoles como los fundadores y los garantes de la identidad nacional. Las festividades nacionales son organizadas por un comité conformado por funcionarios de $\mathrm{NICH}$ de varios rangos. En esa ocasión el país celebraba su aniversario de independencia número 35 bajo el lema: sovereigh and strong, together as one (soberanía y fuerza, juntos como uno). Las calles y avenidas principales estaban adornadas con serpentina y anuncios con los colores rojo y azul. También con el escudo de Belice que representa a dos hombres: uno mulato o creole y otro negro, con un remo y un hacha bajo un árbol de caoba, abrazados alrededor de la frase en latín: sum umbra floreo (bajo la sombra florezco) y banderas que ondeaban con el viento. La víspera del 9 de septiembre en varias cabeceras municipales de los principales distritos del país se instalaron escenarios para la declaración del 10 de septiembre, promovido recientemente en $\mathbf{2 0 0 8}$ por el gobierno de turno como día nacional, para conmemorar el evento de la Batalla de St. George's Caye, de 1798, fecha en que los británicos colonos, conocidos como los baymen, defendieron el asentamiento de los ataques de los españoles quienes frecuentemente les obligaban a evacuar. Durante la noche, en San Ignacio, un pequeño pueblo al sur-occidente de Belice que limita con Guatemala, conformado por mestizos, creoles y mayas, más de un centenar de personas se instalaron en "el parque del amor" para celebrar 
la inauguración de las festividades nacionales. En el centro del parque una tarima pequeña con escudos, banderas y juegos pirotécnicos daba la bienvenida a la concurrencia que bailaba ritmos afro-caribeños como la Punta rock, el soka y el calipso. Las personas bebían cerveza nacional Belikin y ron, y había algarabía por doquier.

La luz de la luna llena iluminaba la explanada del parque. El bramido suave de las aguas del rio Belice que dividen el pueblo en dos, se adentraban por la exuberante vegetación de las Maya Montains de las cuales emergen dos zonas arqueológicas mayas imponentes: Cahal Peh y Xunantunich, a solo unas millas del pueblo, que atraen a miles de turistas durante todo el año. Las personas agrupadas de acuerdo a su cercanía hablaban entre si y departían con los de sus grupos: los creoles, o población negra, junto con los suyos y los mestizos hacían lo mismo a su vez. A veces los más jóvenes de cada grupo intercambiaban algún saludo o pedían fuego para encender sus cigarrillos para luego reincorporarse a sus respectivos grupos. De pronto, la voz del animador llamó al silencio, cesó la música y las personas se agruparon en pos de la tarima. Un hombre afro beliceño, pidió a todos que inclinasen el rostro y en actitud solemne empezó una oración para dar inicio al acto. Todos oraban en silencio mientras algunos se tambaleaban ya bajo los efectos del alcohol. Después, una mujer negra y delgada, una líder política local, que lucía un traje con motivos africanos, collares amarillos, rojos y verdes y un turbante en la cabeza tomó el micrófono y dijo:

Cuando yo estaba en los Estados Unidos me sentía pobre; pobre porque no estaba cerca de mi nación y no había nada que celebrar. La batalla de St. George's Caye es un día Nacional porque conmemora la patria, el nacimiento de una nación que se sacudió los ataques de los tiranos, de los españoles que nos quería echar de aquí, que violaban nuestro derecho de ser los fundadores de esta nación. Una nación multicultural, diversa y bella, una nación bendecida por el Señor. Tenemos que celebrar la patria, el origen de nuestras raíces nacionales. Belice es un país pequeño pero rico y bello. Belice es una nación que nos heredaron nuestros ancestros, aquella gente "negra" nacida de los baymen que decidieron quedarse aquí y defender esto que nos une hoy. Belice la tierra que le pertenece a los hijos de esos baymen, la tierra de nosotros (Discurso público, 09 de septiembre, 2016, San Ignacio, Belice).

Enseguida los juegos pirotécnicos iluminaron el cielo nocturno mientras se escuchaba de fondo las notas del himno nacional beliceño "Arise, ye sons of the Baymen's clan! ...". Le pregunté a un grupo de personas que estaban viendo los juegos pirotécnicos sobre qué pensaban del discurso de la mujer que acababa de hablar. Una mujer joven, mestiza y dos hombres jóvenes me miraron sorprendidos de que yo les hablara en español y me invitaron de su botella de ron. La mujer entonces me dijo en español:

\footnotetext{
- Belice no es solo la tierra de los creoles, de los hijos de los baymen. Este país es de todos. Además hay mayas, garífunas, menonitas, chinos, spanish, todos. No pueden decir que Belice es solo el país de los descendientes de ellos.

¿Por qué crees que usan ese discurso? Pregunté yo. Mira, lo que pasa es que los criollos, los negros, ellos quieren ser los que mandan aquí. Antes uno no podía hablar español en la calle. Ahora ya es distinto. Ellos tienen miedo de convertirse en una minoría"- respondió uno de los hombres que estaban con la mujer-. Cada grupo de los que están en Belice ha hecho cosas grandes por el país, tiene sus historias, pero eso no se cuenta, no se dice en esos discursos. Siempre aparece la misma gente, los otros es como si no existieran (comunicación personal. Diario de campo. 09 de septiembre, 2016).
}

A partir del lanzamiento de la política cultural por parte del Instituto Nacional de Cultura e Historia (NICH) en el año 2014 se inicia un período en que convergen dentro de 
este proyecto estatal varias apuestas: a) La construcción de una identidad nacional que resultaría de la suma de las etnicidades que conforman la multiculturalidad de la sociedad beliceña. b) Una dialéctica cultural que persigue el desarrollo de la cultura y la cultura para el desarrollo. c) La instalación y el fomento de una lógica auto-gestiva de las etnicidades a partir de la cual las organizaciones étnicas del país empezarían a establecer agendas políticas y culturales propias con el fin de generar recursos para "desarrollar sus culturas" y articularse a la política desarrollista del Estado. Y, por último, d) la reinscripción de unas narrativas de origen y fundación de la nación en las cuales los creoles vuelven a ocupar un lugar protagonístico.

El rescate de la Batalla de St. George's Caye, evento al cual se refería la mujer creole en su alocución patriótica, en la que se resalta el papel crucial de los creoles luchando junto a los británicos por defender el asentamiento de los ataques de huestes españolas en $1978^{10}$, ha sido un proyecto en el que varios sectores oficiales se han volcado con renovado interés. La recién creada asociación de historiadores de Belice con el apoyo de Instituto de Investigaciones Sociales y Culturales (ISCR) han destinado fondos para elaborar una investigación más profunda de aquel evento histórico considerado un mito por algunos sectores, y el acta de nacimiento de la identidad de Belice, por otros.

Igualmente, el lanzamiento de la serie National Heroes and benefactors a partir de la cual se intenta construir un parnaso de héroes de la patria, dirigido fundamentalmente a las escuelas primarias y secundarias del país, tiene el objetivo de rescatar la memoria de varios personajes del Belice contemporáneo que han caído en el olvido y necesitan ser elevados a la categoría de héroes nacionales por sus aportes a la consolidación del país. En ese contexto, el reforzamiento y ensalzamiento de figuras como Philip Goldson y Nurse Vivian Seay, ambos creoles afrobeliceños, ha dejado de manifiesto los intentos oficiales por volver a reforzar la idea del predominio de ese grupo en las narrativas de la identidad nacional. El primero fue declarado héroe nacional en el año 2008. Se le conoce como el fundador del partido UDP, de vocación creole, y quien se declaró abiertamente opositor y crítico del PUP quien encaminó al país a su independencia. Se le conoce también como el defensor de la soberanía nacional y uno de los contradictores más fuertes a la integración de Belice a la región económica centro americana, así como también al reclamo guatemalteco por una porción del territorio beliceño. En 2015 se inauguró en Belmopán la casa-museo Philip Goldson donde los estudiantes van a aprender el legado de un "verdadero nacionalista". Por su parte, la enfermera Vivian Seay fue una mujer creole de la clase media de la ciudad de Belice, quien fundó en 1920 The Black Cross Nurses, una organización social que asistía a los sectores más necesitados de entre la población negra. Fue la segunda mujer honrada con el nombramiento de "miembro de la real orden imperial británica" como una servidora ejemplar de la corona durante su etapa de activismo y una "creole" memorable.

En consecuencia, y siguiendo Paris (1999), dentro de los proyectos oficiales de construcción del nacionalismo que propenden por una identidad nacional, se manifiestan racismos en la medida en que hay claras jerarquizaciones en los accesos a la construcción de una identidad nacional y a las narrativas nacionalistas en el entendido de que estas además de ser "artificios culturales" (Anderson, 1993) son espacios 
de legitimación del poder. Entonces, ¿cómo repercute esto en los procesos de movilización política de las identidades étnicas que actualmente tiene lugar en el país?

A partir de los 90' tanto algunos sectores de entre los creoles como otros grupos étnicos representativos en el país, mayas y garífunas principalmente, se convirtieron en un actor político emergente que buscaba negociar espacios de reconocimiento, movilizando recursos como las identidades étnicas a través del refuerzo de la lengua, celebraciones religiosas, defensa de los territorios y expresiones folk de sus culturas. Ese proceso se articuló con proyectos del Estado que buscaban legitimar un modelo económico basado en el desarrollo del sector turismo en cuyo marco los grupos étnicos también eran vistos como insumos para el desarrollo. Así, el sujeto étnico en el marco de la promoción oficial de la diversidad es pensado desde una lógica auto-gerencial y auto-gestiva. La política cultural promueve la folclorización de las identidades étnicas. Desde la oficialidad se celebran festivales creoles, garífunas, hindúes, mayas, etc. En estos se retrata las expresiones identitarias desde el folclor, la imagen de los grupos étnicos aparece como "postales étnicas", con identidades fijas, esenciales y, sobre todo, como recursos potenciales que pueden "desarrollarse". En algunas de las iniciativas oficiales recientes como The Art Street Festival las imágenes de los grupos étnicos aparecen de forma exotizada y fuera de los contextos cotidianos y materiales en los que esas identidades se desarrollan. Se promueve la creación de mercados locales de artesanías, turismo "étnico" y mantenimiento de estereotipos raciales tales como: "los garífunas aguerridos", "los mayas dóciles", "los creoles fuertes", etc. En ese sentido, los grupos étnicos han entrado en una especie de "competencia" para ganar espacios de representación donde, sin embargo, existe una mezcla de jerarquías y horizontalidades. Las movilizaciones de los grupos étnicos en Belice toman el campo de la cultural como una arena de disputas por la representación. En ese sentido, no significan unos procesos de afirmación y contestación ante el Estado, más bien se articulan y hacen parte de los proyectos de este por legitimarse y reproducirse. Son movilizaciones orientadas culturalmente que buscan instaurar nuevas significaciones y formas de reconocimiento que antes no habían sido consideradas (Perales, 2013), pero sin oponerse radicalmente al Estado y a sus proyectos por promover la diversidad.

Sin embargo, estos procesos entrañan mecanismos de racialización que derivan en formas de racismo cuando primero, son orquestados y promovidos por el Estado; segundo, cuando establecen jerarquías en el acceso a los recursos simbólicos tales como las narrativas nacionalistas que ubican a los creoles en el centro de las mismas; y tercero, juegan con imágenes fijas y esencializadas de las identidades de los grupos étnicos a los que representan tácitamente como "grupos que necesitan desarrollar su cultura". La identidad es antes que nada un posicionamiento (Hall, 2003), por lo tanto, es política en la medida que implica procesos de afirmación de esos posicionamientos con miras a ser reconocida. De modo que las movilizaciones étnicas en Belice son a la vez formas de posicionamiento que buscan dentro del Estado mismo, y no fuera de él, espacios del reconocimiento como una vía para acceder a los recursos sociales básicos. 


\section{Conclusiones}

En este texto se intentó mostrar la relación entre un racismo estatista y las iniciativas de construcción nacional auspiciadas por el Estado. Dentro de las mismas, los "creoles" son tomados como símbolos de la beliceñidad y los demás grupos étnicos siguen ocupando una posición periférica dentro de la conformación de narrativas nacionalistas. En ese sentido, el caso de este grupo sirve para cuestionar las nociones sobre la producción social de la negritud y la afrodecendencia (Gudmundson, 2012). La "negritud" más que se una construcción fija de marginación de las poblaciones de origen africano que ocupan posiciones subalternas en los marcos de las sociedades nacionales, es antes que nada, una construcción histórica que juega con las imágenes de lo "negro" y las entremezcla con aspectos de clase imbricados con elementos étnico-racializados. Los creoles en ese sentido, representan un estatus ambivalente. Por un lado, son un grupo heterogéneo que sufrió los embates del colonialismo el cual modeló relaciones racistas y excluyentes entre ellos mismos. Por el otro, gozan de algunas posiciones predominantes en los espacios de construcción de narrativas nacionalistas. Son tomados como símbolos de la nación y a la vez, gran parte de ellos, padecen los embates de la pobreza, la exclusión y la desigualdad en la que se encuentran la mayoría de los grupos étnicos en Belice. Sin embargo, sus procesos de movilización nos muestran como grupos afrodescendientes, comúnmente excluidos de los espacios de poder, pueden entablar relaciones cercanas con éste y movilizar narrativas identitarias que les garantizan al menos ciertos privilegios en los accesos a los recursos simbólicos de la nación como la "cultura nacional" y sus derivados.
Por su parte, el sujeto étnico que se piensa desde la promoción oficial de la diversidad en Belice es representado desde nociones esencialistas, fijas de la identidad y como un recurso para el desarrollo del país, el cual ha apostado por un proyecto de Estado que ve en el turismo una fuente de "desarrollo". En ese contexto los grupos étnicos transitan hacia la mercantilización etnicidad (Comaroff \& Comaroff, 2009) y aparecen bajo una imagen armónica de convivencia entre los mismos, omitiendo las tensiones y las desigualdades entre ellos. Aunque la movilización étnica de garífunas y mayas, principalmente, basada en el refuerzo de la lengua, expresiones folk de la cultura, reafirmación de religiosidades y refuerzo de formas propias de administración de la tierra y el territorio son auténticas muestras de resistencias ante los embates neocolonialistas del capital global económico, esta movilización también se inserta en las lógicas globales de las identidades étnicas y su mercantilización. En ese tenor, el Estado beliceño no desaparece de su ámbito de "forjador de identidades", sino más bien arbitra el juego de las afirmaciones étno-políticas en un "dejar hacer" (Cunin \& Hoffmann, 2014) y un "apoyo" limitado. Este proceso transita lentamente hacia el reconocimiento de las identidades étnicas, pero sin políticas claras de redistribución de recursos orientadas étnicamente. Es decir, existe un «multiculturalismo discreto» en la medida en que hay discursos, políticas culturales y acciones estatales que enfocan la diversidad étnica, pero sin programas sociales concretos para paliar las desigualdades en las que se encuentra la mayoría de esos grupos. 


\section{Notas}

${ }^{1}$ Los garífunas son un grupo étnico producto del mestizaje entre indígenas arahuacos y caribes con africanos traídos a América durante el siglo XVI. Durante un naufragio ocurrido alrededor de la primera mitad de ese siglo - momento referido en la memoria oral de muchos miembros de la etnia-, varios de ellos llegaron a las Antillas menores, en específico a la isla de San Vicente donde se unieron a los nativos caribes que resistían a la dominación colonial tanto de franceses como de ingleses posteriormente. La isla de San Vicente, cerca del subcontinente suramericano, se convirtió en un refugio para muchos esclavizados africanos que tempranamente huían del sistema de esclavitud implantado por franceses e ingleses como parte de una economía de plantación en varias de las Antillas del caribe como Haití, Guadalupe y Martinica entre otras. Después de la invasión de los británicos a la Isla de San Vicente, los garífunas, llamados los Caribes Negros, fueron deportados, al ser considerados enemigos del imperio, hacia Jamaica y luego a la Isla de Roatán, en la costa de Honduras, alrededor del año de 1796. Un número de 2500 arribó finalmente al litoral centroamericano por autorización de las autoridades españolas quienes les pidieron a cambio ser sus soldados. A partir de ahí, los garífunas se extendieron por varias villas y comunidades desde Nicaragua, pasando por Honduras, Guatemala y Belice. En 1802, un pequeño grupo de ellos se asentaron al sur de Belice, antes llamada la Honduras Británica, en la localidad de Seine Bight, Punta Gorda hasta conformar un grupo sólido que el 19 de noviembre de 1832 se asentó definitivamente en el distrito sureño de Stann Creek, en lo que hoy se conoce como Dangriga, donde se encuentra la comunidad más grande de ellos. Han conformado organizaciones etno-civiles como el National Garifuna Council y en 2001 fueron declarados por la UNESCO como patrimonio Inmaterial de la Humanidad por la preservación de su lengua y de varias prácticas culturales. Actualmente, los garífunas son fuertes actores sociales y políticos vinculados a áreas importantes de la vida nacional como la docencia, la enfermería y algunas diputaciones políticas en Belice. Para ampliar información ver (Izard, 2003, 2004; Cayetano \& Cayetano, 1997).

2 En 1919, ocurrieron los primeros disturbios contra el régimen colonial británico protagonizados por soldados beliceños que participaron en la primera guerra mundial los cuales, a su regreso, iniciaron un debate público denunciando el racismo y su tratamiento como "ciudadanos de segunda categoría" al no reconocerse los privilegios que habían ganado al servir a la corona durante la guerra. Aquellos soldados fueron influenciados por la ideología pan-africanista de Marcus Garvey, cuyo movimiento, el Universal Negro Improvement Association (UNIA por sus siglas en inglés), significó el comienzo de un proyecto racial en Belice con orientación nacionalista (Devon, 2012), mismo que fue duramente perseguido y censurado por las autoridades coloniales (Ashdown, 1990). Aquellas primeras movilizaciones derivaron en organizaciones "negras" de enfermeras y de servidores públicos que empoderaron a la población de origen africano en el país intentando paliar las desigualdades en las que se encontraban. Después, en 1969 Evan X Hyde, un intelectual creole afrobeliceño de la clase media, fundó el 9 de febrero el United Black Assotiation for Develoment (UBAD), proyecto que desafío a la elite blanca y creole quienes habían acaparado los recursos de la nación y mostraban un menosprecio por las identidades negras de origen africano. A través del Amandala, el diario fundado por el intelectual, se establecieron formas de movilización contra el colonialismo y el racismo que derivaron en un apoyo de la población negra urbana a las aspiraciones políticas del líder beliceño y significaron unos nuevos cuestionamientos al orden político y económico de la sociedad beliceña.

${ }^{3}$ Según la Panamerican Health Organization (PAHO) (1998), el $42 \%$ de la población está clasificada como pobre en el país. El $16 \%$ vive en condición de pobreza extrema concentrada principalmente en las áreas rurales. El país sigue atrasado en las luchas contra la hambruna. Hasta 2009 Belice era el país que tenía tasas de prevalencia de contagio de SIDA más altas en américa central. Igualmente, persisten las desigualdades de las comunidades rurales por problemas relacionados con el transporte y las vías de acceso y comunicación. El país no cuenta con una política de medicamentos por lo que hay una carencia de fármacos e insuficiente personal médico para cubrir los casos de enfermedades contagiosas que son las más frecuentes en el sistema sanitario del país. Por otra parte, los índices de violencia revelan que el principal problema son las tasas elevadas de homicidios. Según el Estudio Mundial sobre el Homicidio de la ONU (2013), Belice es el tercer país con más prevalencia de problemas de pandillas con una tasa de homicidios de $44.7 \%$. Además de los problemas de tráficos de personas, estupefacientes, tiroteos, asaltos, robos y ataques con granadas que son frecuentes en el país.

${ }^{4} \mathrm{~A}$ pesar de que este trabajo reporta datos etnográficos que remiten a la cotidianidad de algunas dinámicas sociales beliceñas relacionadas con el racismo, la elaboración de nacionalismos y la movilización étnica, su enfoque es un intento de articular una perspectiva macro con una micro sobre el tema del racismo. Sin embargo, esto no se logra a profundidad y ello constituye una de sus limitaciones. Los análisis están mucho más enfocados a componentes estructurales a nivel de análisis del Estado y su función en los proyectos de construcción nacionalista que a una perspectiva interaccionista que se concreta en la cotidianidad de las relaciones sociales. Empero, no soslayo la importancia de éste último enfoque para contextualizar de manera más adecuada la existencia y los entramados del racismo en Belice.

${ }^{5}$ En estos tratados se ratificaba el dominio español sobre los territorios beliceños. Sin embargo, los españoles nunca se instalaron en Belice y, en su lugar, permitieron a los británicos realizar actividades de extracción y acarreo de madera para exportación bajo la condición de no establecerse, no desarrollar agricultura ni 
construir fortines o baluartes para defensa militar.

${ }^{6}$ Anterior al auge de la Caoba en Belice ya existían africanos esclavizados. Los primeros reportes datan de 1724. Sin embargo, su número, aunque superaba al de los hombres "blancos" era menor al que alcanzaría posteriormente durante la última parte del siglo XVIII y todo el siglo XIX.

${ }^{7}$ Actualmente "creole" se considera a todo aquel que refiere tener entre sus ancestros personas africanas o afrodescendientes en unión con cualquier otro grupo étnico-racial. Esta definición marcadamente inscrita en una ideología colorista, remarca subrepticiamente el componente "negro" para la identificación de lo "creole". Por su parte, "creole" no debe confundirse con "criollo", que en Latinoamérica hispana se refiere a los hijos de españoles nacidos en el continente americano los cuales se distinguían de los españoles peninsulares de España. Por esa razón en este texto mantendré la escritura / creole/ en vez de criollo para no confundir a los lectores.

${ }^{8}$ Aquí las traducciones del inglés son nuestras.

${ }^{9}$ Mr. Pinelo es funcionario público del Instituto Nacional de Cultura e Historia. Es una de las personas que trabaja en los proyectos oficiales para diseñar e implementar proyectos de corte nacionalista en Belice mediante el trabajo historiográfico sobre la revisión de eventos que fueron cruciales para definir la fundación de Belice como asentamiento y colonia británica. La construcción de relatos históricos de corte nacionalistas es una de las estrategias de las

\section{Referencias bibliográficas}

7NewsBelize. 15 de mayo, 2017. Recuperado de: http:/ www.7newsbelize.com.

Abrams, P. (1988). Notes on the Difficulty of Studying the State. Journal of Historical Sociology, (1), 59-89.

Anderson, B. (1993). Comunidades Imaginadas: reflexiones sobre el origen y la difusión del nacionalismo. México: Fondo de Cultura Económica.

Anderson, M. (2007). When afro becomes (like) indigenous: Garifuna and Afro-Indigenous Politics in Honduras. Journal of Latin American and Caribbean Anthropology, (12), 384-413.

Ashdown, P. (1990). Garveyism in Belize. Belize City: Society for the Promotion of Education and Research, SPEAR Reports.

Barth, F. (comp.) (1976). Los grupos étnicos y sus fronteras. La organización social de las diferencias culturales. México: Fondo de cultura Económica.

Belize Census Report (2010). Belize Statistical Office. Belmopán.

Belize Cultural Policy (2014). National Institute of Culture and History. Belmopán.

Barnnett, C. (2001). Defining Etnicity in Belize: Understanding our history. Paper Conference. Recuperado de: http://www.open.uwi. edu/sites/default/files/bnccde/belize/conference/papers/Barnett.html.

Billig, M. \& Núñez, R. (1998). El nacionalismo banal y la reproducción de la identidad nacional. Revista Mexicana de Sociología, 60 (1), 37-57. elites dirigentes, creoles en su mayoría, para fortalecer su papel dentro de las narraciones oficialistas de identidad nacional. Estos trabajos son luego socializados y hacen parte de los contenidos curriculares de las escuelas en Belice.

${ }^{10}$ Este evento fue considerado como el acta de nacimiento de la Honduras Británicas (Encalada \& Awe, 2010). Durante la última década del siglo XVII, los españoles habían intentado desalojar a los británicos de los territorios de Belice. Sin embargo, del 3 al 10 de septiembre de 1978, los hombres británicos apostados en un pequeño Cayo a unas millas de la ciudad de Belice, llamado Cayo San Jorge, decidieron hacer frente a los ataques de los españoles. Durante más de 2 horas hubo unos enfrentamientos entre británicos y españoles en sus flotas navales. Los últimos acabaron retirándose por no poder someter a los primeros. Medio siglo después, un comité de celebraciones coloniales en Belice City, encabezado por Absalom Hyde y otros creoles de clase media beliceña retomaron este evento como "la heroica contribución de los Baymen y sus esclavos" a la consolidación de Belice (Shoman, 2009). En ese marco, se resaltó el supuesto papel de los creoles y esclavos "negros" en la defensa del territorio junto con sus "amos". Este relato se ha vuelto a rescatar por la actual elite política dirigente, conformada mayoritariamente por personas "creoles" con el fin de re-centrar el papel de los creoles en las narrativas que dan origen a la identidad de la nación beliceña.

Bolland, N. (1992). Belize: Historical Setting. En Merrill T. (Ed.) A Country Study: Belize. (155-187).Washington: Library of Congress Federal Research Division.

(1988). Colonialism and Resistence in Belize: Essays in historical Sociology. Belize: Belize Press.

Bristowe, L. \& Wright, P. (1888). Handbook of British Honduras for 1888-1889. Second Edition. London: William Balckwood and sons.

Bulmer-Thomas, B. \& Bulmer-Thomas, V. (2012). The Economic History of Belize from the 17th century to Post-independence. Belize: Cobola Books.

Cayetano, S. \& Cayetano, F. (1997). Garifuna History, Language and culture of Belize, Central América and the Caribbean. Belice: BRC.

Comaroff, J. \& Comaroff, J. (2009). Three or four Things about ethno-futures. En Ethnicity, inc. (6-21). Chicago: The University of Chicago Press.

Cunin, E. \& Hoffmann, O. (2014). Belize: Políticas Públicas e gestao de la pluralidade étnica, revista de estudos e pesquisas sobre as américas. 8 (1) 52-71.

Cunin, E. (2010). Los criollos de Belice: ¿Encarnación de la identidad nacional o afirmación étnica? En Hoffmann, O (coord.). Política e identidad: afrodescendientes en México y América Central. (157-187). México: INAH-UNAMCEMCA- IRD.

Devon, L. (2012). Belizean Racial Project: A preliminary Explorations of Black Racial Project. Tesis de maestría en Artes. Kansas: 
University of Kansas.

Encalada N. \& Awe J. (eds). (2010). St. George's Caye. The Birthplace of a Nation. Belmopan: NICH Occasional Publication.

Judd, K. (1992). Elite reproduction and Ethnic Identity in Belize. Tesis de doctorado. Wolf. E. Adviser. New York City: University of New York.

(1990). Who will define us? SPEAR REPORT 4 Second annual studies on Belize conference. México: Cubola Production.

Gudmundson, L. (2012). La Negritud en Centro América: entre Razas y Raíces. San José de Costa Rica: EUNED.

Grünberg, G. (2002). Limitaciones y avances para el control y gestión integral de los territorios indígenas en Centroamérica". En OXFAM / Fundación Ford (ed.) Pueblos indígenas de américa latina: retos para el nuevo milenio (CD-ROM). Lima: Fundación Ford.

Hall, S. (2003). Introducción: ¿quién necesita la identidad? En Hall, S. \& Du Gay, P. (comp). Cuestiones de la identidad cultural. pp. 13-38. Buenos aires: Amorrortu.

Hoffmann, O. (2008). Entre la etnización y la racialización: los avatares de la identificación entre los afrodescendientes en México. En Castellanos, A. Racismo e Identidades. Suráfrica y Afrodescendientes en las Américas. (163-175). México: UAM-Iztapalapa.

Hyde, E. (1970). The crowd called UBAD: the story of a people's movement. Belize City: Modern Printers.

Iyo, A. (2000). Toward's understanding Belize's multi-cultural history and identity. Belmopan: University of Belize.

lyo, A., Froyla, T. \& Humphreys, F. (2007). Belize: A new Vision: African and Maya Civilizations: the Heritage of a new nation. Belize City: Factory Books; Image Factory and art foundation.

Izard. G. (2010). Garífunas y Seminoles negros, culturas transfroterizas. Cuadernos sobre relaciones internacionales, regionalismo y desarrollo, 5 (10), 171-192.

(2004). Herencia y etnicidad entre los Garífunas de Belice. Revista Mexicana del Caribe, (17) 95-127.

(2003). La construcción política de la identidad garífuna en el Belice contemporáneo. Revista de las Americas, historia y presente, (1), 61-81.

López, P. (2011). Alterité intimes, altérité éloignées: la greffe du multiculturalisme en Amérique latine. Critique Internationale Sommaire, (51), 171-187.

Macpherson, A. (2003). Imagining the colonial nation: race, gender and middle-class politics in Belize. 1888-1898. En Appelbaum, N., Macpherson, A. \& Rosemblatt, K. (eds) Race and Nation in modern Latin America. pp. 108-131. USA. University of North Carolina Press.

Márquez, M. (2011). Perspectivas teóricas para abordar la nación y el nacionalismo. Papel Político, 16 (2), 567-595.

Medina, L. (1997). Defining difference, forging unity: the co-construction of race, ethnicity, and nation in Belize. Ethnic and Racial Studies, 16 (4), 757-780.

Murray, R. (2006). Family and people all Well. An account of the Ocurrences in the Business of Mahagony and Logwood Cutting in the Bay of Honduras in 1789. Benque Viejo del Carmen, Belize: Cubola Books.

Organización de las Naciones Unidas (ONU). (2013). Estudio Mundial Sobre el Homicidio. ONU.

Organización Panamericana de la Salud (PAHO). (1998). Salud en las Américas. Belice: Organización Mundial de la salud.

Paris, M. (1999). Racismo y nacionalismo; la construcción de identidades excluyentes. Política y Cultura, (012), 53-76.

Phillips, M. (ed.) (1996). Belize: select proceeding from the second interdisciplinary conferences. Lanham, New York, London: University Press of America.

Scott, J. (1998). Seeing Like a State: How certain schemes to improve the human condition have failed. Yale: Yale University Press.

Steinmetz, G. (1999). Introduction. Culture and the State. En Steinmetz, G. (Ed), State/Culture. State Formation after the cultural Turn. pp.1-49. London: Cornell University Press.

Shoman, A. (2009). Historia de Belice: el surgimiento de una nación centroamericana. Trad. Oriel Sierra Santiesteban. México D.F: UNAM - CIALC. (2000). Thirteen Chapter of a History of Belize. Belize: The Angelus Press Limited. (1987). Party Politics in Belize, 1950-1986. Benque Viejo del Carmen: Cubola.

Smith, A. (2000). Nacionalismo y Modernidad. Madrid: Ediciones Istmo.

Toussaint, M. (2009). Entre los vecinos y los imperios, el papel del Belice en la Geopolítica regional. En Cunin, E. \& Hoffamnn, O. (coord.) Etnicidad y nación; debate alrededor de Belize. Cuaderno de trabajo $N^{\circ}$ 5. México: Proyecto AFRODESC.

(1993). Belice una historia olvidada. México: Instituto Mora. 